\title{
Entry into Auctions: An Experimental Analysis
}

\author{
Seda Ertaç* \\ Ali Hortaçsu ${ }^{\dagger}$ \\ James W. Roberts ${ }^{\ddagger}$
}

June 1, 2009

\begin{abstract}
This paper investigates entry decisions into first and second price auctions using an experimental design to extract information on willingness-to-pay to enter (WTE). We find that subjects tend to overpay to enter both auction formats. In particular, if the subjects believe they will be bidding against bidders following the risk-neutral Nash strategy, their WTE is greater than the optimal risk-neutral amount $97 \%$ of the time for first-price auctions (FPA) and $90 \%$ for second-price auctions (SPA). If they believe that they are bidding against subjects who bid as do the other subjects, they submit a WTE that is too high $92 \%$ of the time for FPA and $69 \%$ of the time for SPA. We also find, in line with previous studies, significant overbidding in both the FPA and SPA. We then investigate whether introducing risk aversion (RA) or "joy of winning" (JOY) can explain the joint observation of over-entry and overbidding. In particular, using bid data alone, we structurally estimate three models, one allowing RA only, one allowing for JOY only and one allowing for both RA and JOY. While a model with JOY alone overestimates WTE, we find that RA alone can explain $38 \%$ of WTE but a model with both RA and JOY (where RA is estimated using FPA bids, and JOY is estimated using SPA bids) can explain $65 \%$ of WTE. Moreover, JOY appears to explain nearly all of the of the male WTE but only $44 \%$ of the female WTE.
\end{abstract}

JEL CODES: C91, D44, D81

Keywords: Laboratory Experiment, Entry, Auctions, Risk Aversion, Joy of Winning, Gender

*Department of Economics, Koç University. Contact: sertac@ku.edu.tr.

${ }^{\dagger}$ Department of Economics, University of Chicago. Contact: hortacsu@uchicago.edu.

${ }^{\ddagger}$ Department of Economics, Northwestern University. Contact: j-roberts2@northwestern.edu.

We would like to thank John List, Aviv Nevo, Rob Porter and participants of the 2008 International Meeting of the Economic Science Association for helpful comments and suggestions. Any errors are our own. 


\section{Introduction}

From a mechanism design perspective, it is important to understand the determinants of entry and their effect on behavior in auctions. This concern may be greater when agents are heterogenous, potentially in multiple dimensions. In many economic contexts, the choice of participating in different market mechanisms is available to individuals interested in purchasing an object. For example, one can buy the object at a posted price in a store or participate in an online auction. Within auctions themselves, there is considerable variety along many dimensions, such as the type of auction mechanism (e.g. first-price, second-price, Dutch, open auction), the number of bidders, the distribution of valuations, the availability of information, the presence of an outside option, etc. The pool of participants in real-life auctions is "selected", and the sample of bidders who choose to participate in a certain auction may have different traits and behave differently than if a random sample of individuals were asked to participate in that auction. While the theoretical auction literature has addressed the endogeneity of entry (see for example Levin and Smith (1994)), only recently have the empirical (see, for example, Athey et al. (2004) or Bajari and Hortaçsu (2003)) and experimental auction literatures begun to confront this issue. One exception in the experimental literature is Lucking-Reiley (2005), which itself points out that the vast majority of the experimental auction literature fixes the number of auction participants. Given that there is considerable individual heterogeneity across dimensions such as risk-aversion, competitiveness, rationality or experience, it is likely that auctions with different characteristics will attract different types of participants, which may change equilibrium predictions on bidding and the seller's expected revenue. This paper presents a series of laboratory experiments aimed at better understanding the determinants of auction entry. We document willingness-to-enter into auctions that greatly exceeds risk neutral expected payoffs from these auctions. We then seek to explain this over-entry phenomenon, considering different types of preferences. ${ }^{1}$ We find support for a model that includes "joy of winning", which refers to an extra utility received from winning the object in an auction. As the opening quotes suggest, emphasizing this type of excitement or joy is a strategy that is actually used to lure potential auction participants into entering auctions, rather than buying the item elsewhere at a fixed price, which is very similar to the decision problem faced by the subjects in our experiment.

Our experimental design is based on the elicitation of subjects' willingness to enter an auction and their bids upon entry, across different auction types. In each round of the experiment, participants are asked to report the maximum amount they would be willing to pay to enter into that round's auction (WTE), where they will compete with computerized "virtual" bidders for an object. The type of auction format and the amount of information available about the auction varies, as will be explained in detail in the experimental design section. We use the Becker-DeGroot-Marschak procedure to elicit the WTE in an incentive compatible way: after subjects report their maximum WTE, a random entry cost is drawn, and if this cost falls below the stated WTE, the subject enters

\footnotetext{
${ }^{1}$ Another paper which seeks to further develop the relationship between entry, bidding behavior and individual characteristics is Palfrey and Pevnitskaya (2008).
} 
the auction. If the entry cost is above the WTE, then she stays out and receives a fixed payoff.

We find substantial over-entry into auctions. The first piece of evidence that bidders over-enter auctions comes from our analysis of bidders' stated WTE in a context where they believe they are competing against virtual bidders. Bidders are willing to pay "too much" in this context as much as $97 \%$ of the time in first-price auctions (FPA) and $90 \%$ of the time in second-price auctions (SPA).

The second piece of evidence that bidders over-enter comes from our dropping the assumption that bidders believe that they are bidding against virtual bidders and instead believe they are actually bidding against bidders who bid like they do. Using the subjects' empirical bid distribution, we show that even here bidders still are willing to enter too often and would do better by stating a lower WTE. In fact, their entry can be rationalized against this bid distribution only $8 \%$ of the time for FPA and $31 \%$ for SPA. Each of these results on over-entry provide scope for a "joy of winning" (JOY) effect to enter the model of auction participation and bidding behavior.

Like other experimental studies, we also find evidence for overbidding in the bid data. In the second-price auction, the well-known dominant strategy is that bidders ought to bid their values regardless of risk attitudes. However, over $50 \%$ of the time subjects bid more than their assigned value, and when they overbid, they do so by a large amount: on average they bid $27 \%$ more than their valuation. Also, on average, men are more likely to overbid in these auctions than women by $11 \%$. This overbidding result in the SPA suggests a place for JOY in models of bidding behavior.

Another piece of evidence for a potential JOY effect comes from a feature of our experiment which allows subjects to select into auctions. Palfrey and Pevnitskaya (2008) show that in models with risk aversion (RA) alone, more selected samples of bidders ought to bid more aggressively, i.e. bid a lower fraction of their valuation, in first price auctions. The intuition is that because the participants that entered the auction (which incorporates a risky payoff) had a higher tolerance for risk, they will behave consistently with this risk-loving profile when they bid by bidding more aggressively. Our data generate the opposite result. When looking at first price auctions, we measure how selected a sample is in multiple ways and show that bidders who had a higher willingness-toparticipate in auctions do not bid more aggressively, and, if anything, bid a greater percentage of their valuation. This finding can be rationalized by incorporating JOY at the entry stage, since the subjects' outside option of not entering is receiving a fixed payoff from which any JOY effect will be absent. ${ }^{2}$

As suggested, to justify these findings on over-entry and overbidding, we present a model that incorporates JOY and RA in bidders' choice of whether to enter an auction and how they ought to bid following entry. Functional form assumptions on the way JOY enters the model are necessary, but we can incorporate a wide range of functional forms, not just additive (as has been done elsewhere in the literate see Cooper and Fang (2008)). In practice we use both additive and multiplicative functional forms to include JOY in our model. We then seek to rationalize what we have previously referred to as "over-entry" using the model. We show that including JOY along with RA is vital in matching the observed entry behavior and that it appears to play a greater role in driving

\footnotetext{
${ }^{2}$ Below we explain why our design may generate conflicting results with those in Palfrey and Pevnitskaya (2008).
} 
men's entry decisions than women's. We use bidding in SPA to identify a JOY parameter since the dominant bidding strategy in these auctions is to bid one's value regardless of risk attitude. We then use the bidding data in FPA to estimate a RA parameter conditional on JOY. Then we seek to explain subjects' stated WTE using models that incorporate RA alone, JOY alone and both RA and JOY. While a model with JOY alone overestimates WTE, we find that RA alone can explain $38 \%$ of WTE but a model with both RA and JOY (where RA is estimated using FPA bids, and JOY is estimated using SPA bids) can explain $65 \%$ of WTE. Moreover, JOY appears to explain nearly all of the of the male WTE but only $44 \%$ of the female WTE.

Section 2 reviews the relevant literature, section 3 explains the experimental design, section 4 presents evidence of RA and JOY in the subjects' behavior, section 5 presents our modeling attempt to include and then estimate JOY and RA and section 6 concludes. All tables, figures and derivations appear at the end.

Before moving on, however, we note that while economists have only recently begun to focus on "joy of winning" effects in auctions, companies using auctions, such as eBay, seem to have long known about this effect. This is evident from commercials and slogans such as eBay's promotional activity touting that "It's better when you win it" in auctions and that their site helps to "Make shopping exciting" and encourages its customers to "Shop victoriously." 3

\section{Related Literature}

While the current paper is one of the first to analyze entry into auctions, it is related to two main strands within the large experimental literature on auctions: studies on the determinants of bidding and studies on selection. Our experiment explores the effects of the number of bidders, the amount and timing of information about the number of bidders and valuation for the object, and individual characteristics such as gender and prior experience with auctions in real life, in both FPA and SPA.

A large body of literature about the FPA has focused on explaining overbidding in FPA (compared to the risk-neutral Nash equilibrium), and factors such as risk-aversion (e.g. Cox et al. (1988)), misjudgments of winning probabilities (Dorsey and Razzolini (2003), Issac and James (2000), Armantier and Treich (2006)), and anticipated regret (Engelbrecht-Wiggans and Katok (2005), FilizOzbay and Ozbay (2007)) have been put forward. Using field data, Lee and Malmendier (2008) find that bidders bid more than the price they could purchase an item for and attribute this effect to a "lack of attention" to the fixed price. Additional utility derived from winning an auction have been proposed as a source of overbidding. Focusing on the "joy of winning" an auction as a potential explanation for the overbidding, Goree et al. (2005), find that in a first price auction the explanation fits the data well, but not as well as a quantal response equilibrium risk-aversion model. Joy of winning has also been proposed by Cooper and Fang (2008) as the source of the common observation of overbidding in SPA. We explore joy of winning jointly with risk-aversion in both FPA and SPA contexts in the current paper.

\footnotetext{
${ }^{3}$ eBay commercials and promotional activity, 2007.
} 
Regarding the effect of the number of bidders on bidding, early experimental tests were provided by Dyer et al. (1989) and Kagel and Levin (1993), who found quite strong support for the theoretical comparative statics predictions related to changes in the number of bidders in the FPA. A more recent study by Issac et al. (2007) explores bidding in both FPA and SPA when the number of bidders is unknown, and finds that there is significant heterogeneity in bidding in the FPA but not in the SPA. A modest amount of overbidding in the FPA is observed, which is attributable to riskaversion, but risk-aversion is unable to account for all the observed heterogeneity in bidding. Our paper focuses on studying the effects of uncertainty and compares different informational conditions on bidding, and therefore is related to the more general literature on the effects of information in auctions as well. Two relevant papers in this regard are Andreoni et al. (2007) and Chen et al. (2007). The former analyzes bidding under different amounts of information about rivals' types, and the latter studies the effects of ambiguity about valuation distributions on bidding, with the finding that ambiguity leads to higher bids.

There are significantly fewer papers on endogenous entry and selection, although this area has been attracting considerable attention recently. Papers that model entry have used one of two approaches (see Kagel and Levin (2008)): the first assumes that the entry cost is incurred before the subject learns about his valuation, and the second assumes that the subject knows this information before deciding on entry. Our paper makes this distinction a treatment variable. In the FPA context, Palfrey and Pevnitskaya (2008) study bidding behavior when the number of entrants in an auction is endogenously determined, and the subjects do not know their valuation at the point of entry. The main result is that when the outside option is better, that is, when the sample that ends up entering the auction is more "selected", bidding will be consistent with lower risk-aversion. They also find evidence for excess entry, however, which is difficult to reconcile with the risk-averse bidder model used to explain overbidding. There are also a few papers which have focused on direct comparisons of entry into first-price and ascending auctions. Ivanova-Stenzel and Salmon (2004) directly compare the willingness-to-pay to enter the two types of auctions for subjects who have experience with both formats. They document a strong preference for ascending auctions when the two auctions have same entry cost, but also find that subjects are not willing to pay "enough" to enter into the ascending auction, considering its ex-post profitability relative to the first-price auction. The authors propose a model that posits the same degree of risk-aversion in entry and bidding to explain the data. In a further study (Ivanova-Stenzel and Salmon (2008)), they test and refute loss aversion and the dynamic properties of the ascending auction (as opposed to submitting sealed bids) as other possible explanations. Engelbrecht-Wiggans and Katok (2005), in a series of small experiments, also find that subjects have a preference for the oral ascending auction, but that they underestimate the expected earnings from ascending auctions relative to first-price auctions.

In terms of individual characteristics, gender is an important factor that has been highlighted in some auction studies as well as in studies of related settings that involve competition and/or choice under uncertainty. Chen et al. (2005) find that women bid significantly higher and earn significantly less than men in FPA, consistent with an explanation based on higher risk-aversion. They find, on 
the other hand, that bidding is not significantly different for women and men in the SPA. Given that gender has been found to affect selection into competitive and risky institutions (e.g. Niederle and Vesterlund (2007)), our experiment, by manipulating the availability of information as well as the auction format, could provide important implications for how auction institutions should be designed, especially when the object sold is gender-targeted. Another relevant characteristic that can affect bidding and entry is real-life bidding experience. One paper that is related to this issue is by Garratt et al. (2008), who test for bidding in SPA using experienced eBay participants, and find that they might bring "incorrect" bidding heuristics from their actual experience over to the laboratory. The current paper elicits information on how familiar subjects are with auction institutions using a post-experiment questionnaire and uses this as a control in the analysis of bidding and entry.

Finally, our paper is tied to a growing literature on selection into experiments and markets more generally. Work on improving our understanding of the role that selection plays in well-known experimental contexts includes but is not limited to: Lazear et al. (2006) (dictator games), Bohnet and Kubler (2005) (prisoner's dilemma), Camerer and Lovallo (1999) (entry games), Eriksson et al. (2006) (tournaments and incentivized contracts) and obviously Palfrey and Pevnitskaya (2008) (auctions).

\section{Experimental Design}

The experiment is designed to study entry and bidding, using (1) the type of auction and (2) the amount of information available about the type of auction as treatment variables. The auctions, in turn, differ with respect to auction format (FPA and SPA) and the number of bidders. We first start with the basic building blocks of the experiment that is common to all treatments and then describe the treatments in detail.

\subsection{Design Features Consistent Across Treatments}

Each round of the experiment consists of two stages: the entry stage and the bidding stage. The entry stage elicits subjects' maximum willingness-to-pay (WTE) to enter into the auction, using a Becker-DeGroot-Marschak (BDM) mechanism (Becker et al. (1964). This mechanism works as follows: at the beginning of a round, subjects are given information about the type of auction in which they will participate during that round. The type of auction and the amount of information provided about the auction are treatment variables, as will be explained below. Subjects are then asked to submit the maximum entry cost they would be willing to incur in order to enter the auction. The actual entry cost is selected by the computer randomly from an interval, and a subject enters the auction only if his maximum WTE is greater than or equal to this randomly chosen entry cost. The subjects know that this is the entry mechanism. With this mechanism, it is optimal for subjects to reveal their true WTE, because the stated WTE does not determine how much the subject actually pays to enter, only whether he enters the auction or not. Subjects are not informed 
of the actual entry cost, and only know whether they will participate or not.

In the event that the subject does not participate in the auction, he receives a fixed endowment in that round, and the round is over for her. If he participates, he receives the same endowment, plus any profit he makes in the auction after paying the entry cost. In all auctions, the winner is the highest bidder. The winner's profit is equal to his valuation minus his own bid in the FPA, and his valuation minus the second highest bid in the SPA. Before the auction starts, subjects know their valuation and possibly other information about the type of auction (again, how much information about the auction is revealed before bidding starts is a treatment variable). After this, the subject is asked to submit a bid, and the round ends. At the end of each round, all subjects are given information on whether they won or not (if they entered), and their total earnings in that round.

The auctions used in the experiment are all independent private value auctions, where valuations are drawn uniformly from the distribution [25,100]. The entry costs are drawn from [0, 25]. The distribution of entry costs is such that $20 \%$ of the time the entry cost would be zero, and $80 \%$ of the time it would be a number between 0 and 25 with equal chance. ${ }^{4}$ Subjects who end up participating in the auction bid against "virtual bidders", and not against other subjects. ${ }^{5}$ In each round, auction participants face either 2 or 4 virtual bidders. The virtual bidders are programmed to bid according to risk-neutral Nash equilibrium (NE) strategies in all the auctions.

\subsection{Treatments}

For each auction institution (FPA and SPA), we have 8 treatments that differ in the amount and type of uncertainty inherent in the auction. The sources of uncertainty are: (1) the subject's own valuation and (2) the number of bidders in the auction. The uncertainty about one's own valuation is only present at the entry stage: subjects always learn their valuations before bidding and sometimes know their valuation at the point of entry decision as well. For the number of bidders, we consider cases where:

Case 1 the number of competing bidders is known at the entry stage

Case 2 the number of competing bidders is known to be equally likely to be 2 and 4 at the entry stage and the realization is revealed to the subject before bidding

Case 3 the number of competing bidders is known to be equally likely to be 2 and 4 , but the realization is not revealed to the subject before bidding

Case 4 the probabilities of 2 or 4 competing bidders are not known at the entry stage and are never revealed. In fact, the actual probabilities are that 2 and 4 bidders are equally likely. ${ }^{6}$

\footnotetext{
${ }^{4}$ This was done in order to be able to gather enough data on bidding with a non-selected sample. Notice that this manipulation does not affect the incentive-compatibility of the BDM mechanism used to elicit WTE's.

${ }^{5} \mathrm{We}$ do this is in order to study the effect of uncertainty about the number of bidders on auction entry in a controlled way.

${ }^{6}$ This case is meant to capture the effect of ambiguity in entry and bidding.
} 
Notice that the labeling of the cases is increasing in the amount of uncertainty subjects face about the number of competing bidders they will face. Thus, a treatment is a defined by two uncertainties: (See valuation at entry stage, Case $j, j=1,2,3,4$ ).

\begin{tabular}{lcccc|cccc}
\hline At Entry Stage: & \multicolumn{4}{c}{ First Price Auction } & \multicolumn{3}{c}{ Second Price Auction } \\
\hline Value Known & $\mathrm{C} 1$ & $\mathrm{C} 2$ & $\mathrm{C} 3$ & $\mathrm{C} 4$ & $\mathrm{C} 1$ & $\mathrm{C} 2$ & $\mathrm{C} 3$ & $\mathrm{C} 4$ \\
Value Unknown & $\mathrm{C} 1$ & $\mathrm{C} 2$ & $\mathrm{C} 3$ & $\mathrm{C} 4$ & $\mathrm{C} 1$ & $\mathrm{C} 2$ & $\mathrm{C} 3$ & $\mathrm{C} 4$ \\
\hline$N$ & 486 & 552 & 503 & 552 & 402 & 353 & 385 & 400 \\
\hline
\end{tabular}

The experimental design has both within-subject and between-subject elements: the auction format (first price or second price) is held constant within a session, but in each round within a session, subjects are presented with a randomly-drawn treatment from the 8 treatments.

The experiments were conducted at the California Social Science Experimental Laboratory (CASSEL) at UCLA, using undergraduate students as subjects. ${ }^{7}$ A total of five sessions were run, and 69 subjects participated. Three of these were FPA sessions (41 subjects), and 2 were SPA (28 subjects). 35 participants were male, 34 female. Each subject participated in only one session. A session consisted of 60 rounds, except for one session which proceeded exceptionally slowly and only 36 rounds could be completed. Ten of the 60 rounds were randomly picked by the computer to be compensated, and subjects' payoffs were equal to the sum of their payoffs in these selected rounds. $^{8}$

After the instructions were read, participants played 3 practice rounds before starting to play for real rewards. Sessions lasted roughly an hour and a half. We gave the subjects a survey at the end of the experiment, which asked questions about subjects' prior experience with auctions and about their bidding strategies and also collected some demographic information (the survey questions can be found in the Appendix). Earnings in the experiment were denominated in "points". The exchange rate between points and dollars was 0.04. In addition to earnings from the experiment, subjects were paid a show-up fee of $\$ 5$. Total earnings averaged around $\$ 20$, and participants were paid in cash, in private, after the experiment ended.

\section{A Role for JOY and RA?}

This section presents evidence that JOY and RA ought to be incorporated into models of bidding behavior. It does so by demonstrating that subjects over-enter into and overbid in auctions.

\subsection{Over-Entry}

In this section we present results of over-entry which may be justified by a JOY effect. Each participant knows that if they stay out of the auction they will automatically receive their endowment.

\footnotetext{
${ }^{7}$ The experiment was computerized using z-tree (Fischbacher (1998)), by Avinash Bhardwaj.

${ }^{8}$ The subjects knew that this would be the payout rule and this was done to prevent wealth effects during the experiment.
} 
However, by entering the auction they have the ability to potentially earn more than this, and the greater a subject's valuation, the greater ought to be his willingness-to-enter the auction. The first piece of evidence of over-entry comes from our analysis of the rationality of entry into auctions where the subject believes he will compete against virtual bidders.

To begin, we compare the stated maximum WTE to enter with the theoretical benchmarks. In order to do this, we use data on the actual bidding of the individual subject in conjunction with his WTE for that auction.

Assuming that the individual knows how he will bid once he enters, the perceived probability of winning at the point of entry can be inferred using the actual bids, for subjects who end up entering. ${ }^{9}$ Using the cdf of the valuation distribution and the bidding strategy of the virtual bidders, this probability is given by the following equations. When the number of bidders $(N)$ is known at the point of entry, in the FPA we have:

$$
\operatorname{Pr}(\text { win })_{N}=\left\{\begin{array}{l}
\left.\operatorname{Pr}\left(b_{i}>\frac{N-1}{N}(v)+\frac{v_{l}}{N}\right)\right)^{N-1}=F\left(\frac{N b_{i}-v_{l}}{N-1}\right)^{N-1} \text { if } \frac{N b_{i}-v_{l}}{N-1} \leq v_{h} \\
1 \text { otherwise. }
\end{array}\right.
$$

When the number of bidders is unknown at the point of entry and will never be observed, but its distribution is known (case 3 ), we have: ${ }^{10}$

$$
\operatorname{Pr}(\text { win })=\left\{\begin{array}{l}
\left.0.5\left[\operatorname{Pr}(\text { win })_{3}\right)\right]+0.5\left[\operatorname{Pr}(\text { win })_{5}\right] \text { if } \quad \frac{N b_{i}-v_{l}}{N-1} \leq v_{h} \text { for all } N \in\{3,5\} \\
0.5+\left[\operatorname{Pr}(\text { win })_{5}\right] \quad \text { if } \frac{3 b_{i}-v_{l}}{2}>v_{h} \text { and } \frac{5 b_{i}-v_{l}}{4} \leq v_{h} \\
1 \text { otherwise. }
\end{array}\right.
$$

Theoretically, when a risk-neutral subject $i$ knows his valuation at the point of entry, his maximum WTE should equal his expected payoff in the auction. Therefore, we can calculate the optimal WTE by:

$$
W T E_{i}=\operatorname{Pr}(\text { win })\left(v_{i}-b_{i}\right)
$$

If we then classify the subjects who are willing to pay more than the optimal WTE as overentering, we find that subjects over-enter the FPA $97.18 \%$ of the time. When we add the observations for the case with ambiguity as well, with the assumption that subjects assign equal chance to the two possible numbers of bidders in this case, the over-enty result does not change.

An important point to note in the above analysis is that the calculations were done with the assumption of risk-neutrality for the potential entrant. Notice, however, that if the subject is instead risk-averse, he would be more likely to shy away from entry into the auction, which suggests that the actual rate of over-entry may be even higher. The risk-neutral case given above therefore provides

\footnotetext{
${ }^{9}$ Notice that this strategy cannot be directly applied to case 2, since the number of bidders is unknown at the point of entry but known at the point of bidding, and therefore actual bids cannot be used to rationalize the quoted maximum entry fee in that particular round for that subject. Cases 3 and 4 don't suffer from this because no new information is revealed prior to bidding.

${ }^{10}$ Notice that these formulas would hold for the case with ambiguity (case 4) also, assuming that under ambiguity, subjects assign a $50 \%$ chance to the number of bidders being 2 or 4 .
} 
a lower bound for over-entry observed in the FPA.

For the SPA, since virtual bidders follow the dominant strategy of bidding own value, the probability of winning with a bid $b$ is equal to

$$
F(b)^{N-1}=\left(\frac{b-v_{l}}{v_{h}-v_{l}}\right)^{N-1}
$$

Expected payment in the auction for a bidder with valuation $v_{i}$ who bids $b_{i}$ is then given by:

$$
E\left(\max \left(v_{j \neq i} \mid v_{i} \geq v_{j}\right)\right)=\left(\frac{N-1}{N}\right) b_{i}+\frac{v_{l}}{N}
$$

Given this, defining over- and under-entry in the same way as we do for FPA, we find that in $90.12 \%$ of the cases, subjects overpay to enter auctions.

Finding that in most cases subjects are willing to overpay to enter auctions, we then analyze how much the stated WTE's exceed the theoretical benchmarks we calculate. We find a significant difference here between the two auction institutions: while the amount that subjects are willing to overpay, on average, constitutes $29.1 \%$ of their valuation in the FPA, as opposed to $17.5 \%$ in the SPA (the difference is statistically significant, with p-value $<0.00$ ). Another interesting difference is with respect to gender: while there is no difference in the overpayment propensity across the genders in the SPA (women's average overpayment fraction is $18.8 \%$ whereas men's is $16.6 \%$ ), women's maximum WTE in the FPA imply an overpayment of $32.3 \%$ of valuation (as opposed to men's 25\%). This gender difference in the FPA is again statistically significant (p-value $=0.011$ ).

A caveat to the previous analysis is that bidders believe they are competing against virtual bidders who are playing NE strategies. Suppose instead that bidders believe that they are competing against bidders who bid as they do. We can again test whether bidders are over-entering by examining the rationality of their WTE when measured against the empirical bid distribution generated by the subjects in the experiment. To perform this analysis, using our nonparametric estimate of $\beta_{g, k}$, we first compute our estimate of the bid a bidder would have made in the event that their WTE was below the realized entry cost. To do so we compute a nonparametric estimates of the bidding function $\beta_{g, k}(v), g \in\{$ male, female $\}$ and $k \in\{F P A, S P A\}$ for each gender in each auction format. ${ }^{11,12}$ We then use this function to predict the bid for auctions that the subject was not forced to participate in. That is, let $\widehat{H_{g, k}(b)}$ be the empirical bid distribution pertaining to each sex in each auction format. Then, by simulating auctions $S$ auctions from the relevant bid distribution we can calculate the frequency with which each participant's stated WTE was $e x$ ante rational. Table 1 displays the results. Consistent with the findings assuming participants believed themselves to be competing against virtual bidders, the subjects over-enter. When pooling auctions, subjects over-entered $84 \%$ of the time, but in second price auctions, this was less drastic with participants over-entering only $69 \%$ of the time. In first price auctions, however, the over-

\footnotetext{
${ }^{11}$ Note that we could do this by just using the "free entry" auctions where everyone was allowed to participate.

${ }^{12}$ In practice we use a fifth order polynomial in a bidder's value, conditional on gender and the number of bidders in the auction to estimate $\beta_{g, k}$.
} 
entry was much more pronounced. Subjects over-entered approximately $90 \%$ of the time when they were competing against two other bidders $(N=3)$ and $95 \%$ of the time when they knew they would compete against four other bidders $(N=5)$.

\subsection{Overbidding}

In this section we present results of overbidding which may be justified by a JOY effect. The first piece of evidence of overbidding comes from our analysis of bidding in second price auctions.

Second price auctions are a clear case where JOY can be isolated because risk attitude does not affect the dominant strategy of bidders. This is because the dominant strategy is for bidders to bid their own value regardless of risk attitude. Therefore, overbidding is defined as a subject bidding more than their assigned valuation. 28 subjects participated in the second price auctions. Table 2 summarizes the bidding data from these sessions. The average bid is greater than the average randomly assigned valuation for the object with overbidding occurring $53 \%$ of the time and this is statistically significant at the $1 \%$ level (p-value of 0.000 ). In terms of the magnitude of this effect, conditional on overbidding, the size of the overbid is significant. When bidders overbid they tend to overbid by $27 \%$ of their assigned valuation. To investigate further drivers of this overbidding, Table 3 presents results from a probit model of the event of overbidding on various characteristics including gender and experience in previous auctions such as eBay. The table displays estimated coefficients, controls for within-subject correlation in errors, includes period dummies of length five and includes treatment fixed effects where appropriate. It is clear that males are more likely to overbid by approximately 30\%. Even this fairly coarse test illustrates the potential for JOY to affect bidding behavior. Also note that the tendency to overbid does not seem to diminish as the experiment progresses suggesting that the story is not one tied to a misperception of the probability of winning. If it were we might expect to see this overbidding reduced over time.

To probe more deeply for a JOY effect on bidding behavior in second price auctions, we also investigate bidding determinants. Table 4 displays OLS results of the fraction of a subject's value that he bid as a function of his value and other demographic controls. The table pools all treatments together and includes treatment controls, but each specification was also tested within treatment with no real change to the results. Evident in Table 4, men bid a greater percent of their valuation and across genders this fraction declines with the level of a subject's value. There is also evidence that a subject is less likely to overbid the more experience he has with bidding on eBay. Other self proclaimed attributes from the end of experiment survey do not appear to determine bidding behavior. Taking the results from bidding in second price auctions together, there is evidence of overbidding, potentially stemming from JOY, and that this effect may be greater in men than in women.

The next piece of evidence that there may be scope for JOY to enter the model of bidding behavior comes from our analysis of first price auctions. Given that we have data on auctions where there are differences in the strength of selection, an interesting question is how bidding behavior differs according to one's willingness-to-pay to enter into auctions. Palfrey and Pevnitskaya (2008) 
study a similar question by varying the outside option available to the subjects. We therefore compare bids in the FPA across entry cost, in order to analyze the effects of the strength of the selection. A higher realized entry cost means that the sample will be more selected, since only the bidders who were willing to pay a lot for entering will have entered. Palfrey and Pevnitskaya find that bidders who choose to enter FPA when the outside option is higher are more risk-loving, and therefore bid more aggressively in the auction. This implies that bids will be lower when the sample is more "selected". In our framework, this would correspond to the hypothesis that bidding should be more aggressive when realized entry costs are higher. We test this hypothesis in Table $5{ }^{13}$. The first regression (Column 1) regresses bidding as a percent of valuation in the "PalfreyPevnitskaya case" on the number of bidders, gender and bidding experience, as well as entry cost. This regression yields a positive and significant effect of the cost of entry and the effects of gender, number of bidders and their interaction are significant. Thus we see that auctions for which the entry cost draw was higher leads to bidders bidding a greater percentage of their valuation. While this appears to contradict the findings in Palfrey and Pevnitskaya (2008) the subjects in our experiment do not learn $E$ at the time of bidding. Thus, the closer comparison is when we control for the stated maximum willingness-to-pay, and when we do this, we do not find a significant effect of selection on bidding. ${ }^{14}$ Controlling for selection through the direct inclusion of each subject's stated maximum willingness-to-pay for the auction does not change the results much since the direction of the effect of selection is opposite to that proposed by existing work, although the effect is not statistically significant (Column 2). In each of the specifications we see now that men bid a greater percentage of their valuation than women once the selection effect is controlled for. We also see that men respond less to increased competition than women, and that the selection effect has a marginally lower impact on their bidding behavior than on women's.

We now extend this analysis to the other cases. We run a similar regressions for all the cases where the number of bidders is ultimately observed before bidding and control for selection using the entry cost (Columns 3 and 4). We continue to find that more selected samples bid less aggressively (a higher percentage of their valuation), contrary to the existing hypothesis. This is robust to our differing measures of selection. Taken with the first result that bidders overbid in second price auctions, these results of the absence of the "selection" effect lead us to posit that JOY of winning, combined with RA, plays an important role in determining bidding behavior.

There is also evidence in Table 5 that knowing the number of competitors at the entry stage leads to a more conservative bidding strategy even though the number of bidders are known at the time of bidding. Also, learning there are two, as opposed to four, bidders before one bids, but after one enters, leads to a less aggressive bidding strategy. This is in contrast to not knowing one's valuation at the time of entry which has no residual impact on bidding behavior once it is known. Taken as a whole this may be suggestive of a "spite" motive. ${ }^{15}$ One might think that the

\footnotetext{
${ }^{13}$ We calculate robust standard errors, clustered by subject, in all columns

${ }^{14}$ While men tend to bid a greater percentage of their valuation, the effect of a more selected sample is diminished for them.

${ }^{15}$ See Andreoni et al. (2007) or ? for example.
} 
spite motive is identified by cases where the bidder knows he has a low value before entering, enters anyway and then learns he is competing against four bidders as opposed to two. We can check this by comparing the percent of one's valuation bid when one knows he has a low value but enters anyway in Case 2 when there turn out to be four bidders as compared to Case 1 when he knew there would be four bidders. This test is complicated by risk aversion. All else being equal, the chance of facing two bidders in a first price auction should encourage more risk averse bidders to enter the auction than when they knew they would face four bidders. However, this effect would also cause the bidding conditional on learning that there are four bidders to be greater than when it was pre-announced that there would be four bidders. Thus, there ought to be two effects moving bidders to bid a greater percentage of their valuation in this subset of Case 2 as compared to Case 1. However, when comparing the percent of one's value bid in these two events, as is seen in Table 6 , we see that bidders do not tend to increase their bid by a statistically significant amount when they learn they are competing against four bidders as opposed to two. Furthermore, the effect doesn't appear to depend on the bidders' holding low values, something implied by the spite motive.

These results on overbidding, taken in conjunction with the results on over-entry, provide further support for including JOY and RA into subjects' behavior. It has long been felt that risk aversion alone does not completely explain the frequently observed tendency to overbid in auctions (Kagel (1995)). We concur and now turn towards positing a model that does relies on both RA and JOY in order to justify the facts presented thus far.

\section{$5 \quad$ Model and Structural Estimation}

In this section we augment the standard auction framework to incorporate JOY and RA in a model of entry into, and bidding in, independent private value first price auctions. The is a model of Case 1 where the bidders learn their values prior to entering the auction. In the first stage the bidder learns his value $v$, which was drawn from a distribution $F(v)$, and makes a decision about his maximum willingness-to-pay, $W T E$, in order to enter a first price auction where he will compete against $N-1$ bidders. Then a random number $\phi$ will be drawn and if $\phi<W T E$ the subject enters the auction and places bid $b$ for the object. The subject knows he will participate against risk neutral bidders who know they are facing $N-1$ bidders all of whom draw their values from $F(v)$. Regardless of whether or not the subject wins the auction, he pays $\phi$ out of a budget $E$. If $\phi>W T E$ (ties happen with zero probability) the subject keeps $E$. The bidder's von Neumann-Morgenstern utility function is $u(\cdot)$, with $u^{\prime}(\cdot)>0, u^{\prime \prime}(\cdot)<0$ and $u(0)=0$

We introduce two parameters into the model: risk aversion and joy of winning. Let $\alpha$ be the risk aversion parameter. Below we work with a parameterized version of $u(\cdot ; \alpha)$. Let $\theta$ denote a bidder's "joy of winning" such that conditional on winning the object the consumer now enjoys a value $\hat{v}=h(v ; \theta)$, with $\frac{\partial h(\cdot)}{\partial v} \geq 0$ for all $\theta$ and $\frac{\partial h(\cdot)}{\partial \theta} \geq 0$ for all $v$.

The equilibrium choices that we are interested in are the subjects' choice of WTE and $b$, conditional on entry. We begin with the second stage where the bidder has entered and is selecting his 
optimal bid, $b^{*}$. At the point of bidding, the bidder views the entry cost as sunk when he chooses his bid $b^{*}$ so that:

$$
b_{i}^{*}=\operatorname{argmax}_{b_{i}} u\left(h(v ; \theta)-b_{i} ; \alpha\right) \operatorname{Pr}\left[W i n \mid b_{i}, N, F(v)\right]
$$

where $\operatorname{Pr}\left[\right.$ Win $\left._{i} \mid b_{i}\right]$ is the probability that the bidder will win if he submits bid $b_{i}$ given that he faces $N-1$ other bidders who are playing the risk neutral Nash Equilibrium strategy when values are drawn from $F(v)$. A closed form solution for the optimal bid is derived for the parameters used in the experiment in the Appendix.

At the first stage, the bidder must choose his maximum willingness-to-pay to enter the auction, $W T E_{i}$. This choice will trade off the benefit of staying out of the auction and receiving $E$ for sure with the possibility of winning an auction where the monetary gain could exceed $E$. Let the expected profit of the bidder with value $v$ bidding $b$ when he pays an entry cost $\phi$, faces $N-1$ other bidders with values drawn from $F(v)$ and preferences defined by $\alpha$ and $\theta$ be $\mathrm{E}[\Pi(v, b ; \phi, N, F(v), \alpha, \theta)]$. In equilibrium, knowing his bid conditional on entry will be $b_{i}^{*}(v)$ (dropping the dependence on parameters for a moment), the bidder will choose his maximum willingness-to-pay, $W T E_{i}^{*}$ such that:

$$
E=\mathrm{E}\left[\Pi\left(b_{i}^{*}(v) ; W T E_{i}^{*}, N, F(v), \alpha, \theta\right)\right]
$$

We observe $T_{1}$ first price auctions and $T_{2}$ second price auctions. This section uses only data from Case 1 where bidders observed their valuation at the entry stage. We now seek to explain subjects tendency to over-enter into auctions in a risk neutral environment with no "joy of winning", using the above model. To do so we will need estimates of $\theta$ and $\alpha$. We will use bidding in second price auctions to generate estimates of $\theta$ and bidding in first price auctions for estimates of $\alpha$. However, because we do not observe the same subject bidding in both first and second price auctions, we assume that $\theta_{i}=\theta$ and $\alpha_{i}=\alpha \forall i$. In practice, we allow for subjects with different characteristics $D_{i}$ to have different $\alpha$ and $\theta \cdot{ }^{16}$ At this point we parameterize the function $h(\cdot)$ in the following ways:

Additive $h(v ; \theta)=v+\theta$

Multiplicative $h(v ; \theta)=v \theta$

This parameterization is important for pinning down JOY as will be seen below.

We begin by assuming that we know $\theta$. Having presented evidence of overbidding in first price auctions, we now illustrate the way it identifies RA given estimates of JOY. Using the parameterized version of the model which was employed in the experiment, (importantly, that bidders have CRRA preferences and that $F(v)$ is uniform over $\left[v_{L}, v_{H}\right]$ ), we know (see Equation 9 in the Appendix):

$$
b_{i}=\frac{\alpha v_{L}+h\left(v_{i} ; \theta\right)(N-1)}{\alpha+N-1}
$$

This bidding function forms a mapping between a subject's value and his bid given his RA and JOY parameters. Therefore, for any $\theta$, we can estimate $\alpha$ using nonlinear least squares. Note that

\footnotetext{
${ }^{16}$ In practice we let $D$ include whether the subject was male or female.
} 
if we believed there were no JOY effect, i.e. $h(v ; \theta)=v$, then we could still use bidding data in first price auctions to generate an estimate of $\alpha$. Let $\widehat{\alpha}, \widehat{\alpha\left(\theta_{A}\right)}$ and $\widehat{\alpha\left(\theta_{M}\right)}$ denote the estimates of $\alpha$ assuming no JOY, additive JOY and multiplicative JOY, respectively.

We now turn to forming estimates of $\theta$ which were assumed to be known when estimating $\alpha$. Having presented evidence of overbidding in second price auctions, we now illustrate the way it identifies JOY given parametric assumptions regarding $h(v ; \theta)$. If the bidder's value of winning the auction is given by $h(v ; \theta)$, then the dominant strategy in the second price auction to bid $b=h(v ; \theta)$. Therefore, for known $h(v ; \theta)$, if we observe $\left(v_{i}, b_{i}\right)$ for some bidder $i$ in a second price auction, $\theta=h^{-1}\left(b_{i} ; v_{i}\right)$. Exploiting the two previously mentioned functional forms for $h(\cdot)$, we form estimates $\widehat{\theta_{A}}$ and $\widehat{\theta_{M}}$ (for additive and multiplicative JOY, respectively) using bidding in second price auctions by: $\widehat{\theta}_{l}=\frac{1}{T_{2}} \sum_{i=1}^{T_{2}} h_{l}^{-1}\left(b_{i} ; v_{i}\right), l=A, M$.

Before using these parameters to predict entry behavior into auctions, we present our parameter estimates. We begin by showing our estimates of JOY in Table 7. It is clear that men display a greater JOY than women whether JOY is modeled as additive or multiplicative. This is consistent with the patterns of overbidding in the second price auctions we presented earlier. Our estimates of RA appear in Table 8. The results are consistent with risk averse bidders and the well known result, even after controlling for JOY, that women are more risk averse than men.

With estimates of $\theta$ and $\alpha$ in hand, we can estimate the optimal willingness-to-pay to enter the first price auctions in an attempt to rationalize the over-entry observed in the data. To do so, for each observed value and bid, we find the $W T E$ that solves equation 7 given the estimates of $\alpha$ and $\theta$. Let $\left.\widehat{W T E}, W \widehat{T E\left(\theta_{A}\right.}\right)$ and $\left.W \widehat{T E\left(\theta_{M}\right.}\right)$ denote the estimates of $W T E$ assuming no JOY, additive JOY and multiplicative JOY, respectively.

Table 9 displays the results of this estimation procedure under various assumptions. The first column shows the results when we have only RA affecting bidders. The second and third allow only JOY to affect bidders. The fourth and fifth allow both RA and JOY to affect bidders. ${ }^{17}$ The table displays $95 \%$ confidence intervals for the estimated WTE as a fraction of valuation. These are bootstrapped for the cases with JOY. It is clear that a model without JOY cannot explain the over-entry of bidders and that the model without RA overestimates participants' willingness-toparticipate substantially. This suggests that including both RA and JOY should be important in matching the observed WTE as a fraction of valuation and this is substantiated in the fourth and fifth columns. When we incorporate JOY and RA we move much closer to the observed participation. When we include JOY we explain almost all of the over-entry observed by men but still leave $53 \%$ of the over-entry of women unexplained. Even with no within-subject variation in auction format (FPA vs. SPA) behavior, the model incorporating JOY, either as additive or multiplicative, does a much better job of rationalizing the over-entry.

While the fit of the model is better when we incorporate both RA and JOY, we are now interested in how the residuals from the predicted WTE vary as a function of valuation. Figure 1 plots these residuals as a function of valuation. The curves are fifth order polynomials fitting the plotted data.

\footnotetext{
${ }^{17}$ If we look only at auctions where $\phi=0$, so that all subjects enter, the results are very similar, suggesting that selection is not driving much of the results.
} 
That the curve increases in valuation when we ignore JOY (the first panel) suggests that JOY indeed ought to be included to match this pattern. The second and third panels illustrate that we are predicting too high a willingness-to-enter when we ignore RA. The fourth and fifth panels suggest that while we have not fit the data perfectly, the remaining residuals may be attributable to a "joy of participation" or some other effect which is independent of valuation as the curve does not increase in valuation.

\section{Conclusion}

To the extent that a mechanism designer believes there is heterogeneity among agents, he ought to be concerned with the potential differential impact his design may have on agents of varying types. This paper aims at providing evidence that such concerns are valid in the context of auctions. In this paper we focus on bidders' decisions to enter auctions or opt out and receive a fixed payment. In one of the first studies to focus on entry in auctions, we document severe over-entry. Relative to risk neutral payoffs, bidders over-enter first price auctions $97 \%$ of the time and second price auctions $90 \%$ of the time. We also document the well-known tendency of subjects to overbid. We then seek to explain such behavior through a combination of risk aversion and "joy of winning". We show reduced form facts consistent with the presence of both and then turn to a structural model in an attempt to fit the observed entry behavior of subjects. We show that a model incorporating "joy of winning" alongside risk aversion does a better job in matching the observed entry behavior than a model lacking "joy of winning." This is the first study we know of to propose "joy of winning" to explain not only bidding behavior, but also endogenous entry behavior. Furthermore, we show that adding "joy of winning" seems to match male entry behavior better than that of females. Still, there is unexplained variation in observed entry behavior that we believe may be explained by a "joy of participation" effect, but more research should be brought to bear on the matter. 


\section{Appendix}

$F(v)$ is Uniform $\left[v_{L}, v_{H}\right]$. Conditional on entry, the optimal bidding rule in a first price auction for a bidder with CRRA preferences, i.e. $U(x ; \alpha)=x^{\alpha}$ facing $N-1$ other risk bidders who are submitting bids of the form: $b=\frac{N-1}{N} v+\frac{v_{L}}{N}$ is solved by:

$$
\begin{aligned}
\Pi & =\max _{b_{i}}\left(h\left(v_{i} ; \theta\right)-b_{i}\right)^{\alpha} \operatorname{Pr}\left[\text { Win } \mid b_{i}\right] \\
& =\max _{b_{i}}\left(h\left(v_{i} ; \theta\right)-b_{i}\right)^{\alpha} \operatorname{Pr}\left[\frac{N b_{i}-v_{L}}{N-1}>\max _{j \neq i}\left\{v_{j}\right\}\right] \\
& =\max _{b_{i}}\left(h\left(v_{i} ; \theta\right)-b_{i}\right)^{\alpha}\left(\frac{N b_{i}-v_{L}}{(N-1)\left(v_{H}-v_{L}\right)}-\frac{v_{L}}{v_{H}-v_{L}}\right)^{N-1} \\
& =\max _{b_{i}}\left(h\left(v_{i} ; \theta\right)-b_{i}\right)^{\alpha} \Phi(b)^{N-1}
\end{aligned}
$$

where $\Phi(b)=\frac{N b-v_{L}}{(N-1)\left(v_{H}-v_{L}\right)}-\frac{v_{L}}{v_{H}-v_{L}}$

The associated First Order Condition:

$$
\begin{aligned}
0 & =-\alpha\left(h\left(v_{i} ; \theta\right)-b_{i}\right)^{\alpha-1} \Phi(b)^{N-1}+\left(h\left(v_{i} ; \theta\right)-b_{i}\right)^{\alpha}(N-1) \Phi(b)^{N-2} \frac{N}{\left(v_{H}-v_{L}\right)(N-1)} \\
& \Longleftrightarrow-\alpha \Phi(b)+\left(h\left(v_{i} ; \theta\right)-b_{i}\right) \frac{N}{v_{H}-v_{L}} \\
0 & \Longleftrightarrow \\
0 & \Longleftrightarrow-\alpha\left(b-v_{L}\right)+\left(h\left(v_{i} ; \theta\right)-b_{i}\right)(N-1) \\
b_{i}^{*} & =\frac{\alpha v_{L}+h\left(v_{i} ; \theta\right)(N-1)}{\alpha+N-1}
\end{aligned}
$$

Thus, for any set of parameters we have the equilibrium mapping between bidder values and submitted bids. 


\section{References}

Andreoni, J., Y. Che, and J. Kim (2007). Asymmetic information about rivals' types in standard auctions: An experiment. Games and Economic Behavior 59, 240-259.

Armantier, O. and N. Treich (2006). Overbidding in indpendent private value auctions and misperception of probabilities. Working Paper.

Athey, S., J. Levin, and E. Seira (2004). Comparing open and sealed bid auctions: Theory and evidence from timber auctions. NBER Working Paper.

Bajari, P. and A. Hortaçsu (2003). The winner's curse, reserve prices and endogenous entry: Empirical insights from eBay auctions. RAND Journal of Economics 34(2), 329-355.

Becker, G., M. DeGroot, and J. Marschak (1964). Measuring utility by a single-response sequential method. Behavioral Science 9, 226-232.

Bohnet, I. and D. Kubler (2005). Compensating the cooperators: Is sorting in the prisoner's dilemma possible? Journal of Economic Behavior and Organizations 56, 61-76.

Camerer, C. and D. Lovallo (1999). Overconfidence and excess entry: An experimental approach. American Economic Review 89, 306-318.

Chen, Y., P. Kratuscak, and E. Ozdenoren (2005). Why can't a woman bid more like a man? Working Paper.

Chen, Y., P. Kratuscak, and E. Ozdenoren (2007). Sealed bid auctions with ambiguity: Theory and experiments. Journal of Economic Theory 136, 513-535.

Cooper, D. and H. Fang (2008). Understanding overbidding in second price auctions: An experimental study. The Economic Journal 118, 1572-1595.

Cox, J., V. Smith, and J. Walker (1988). Theory and individual behavior of first-price auctions. Journal of Risk and Uncertainty 1, 61-99.

Dorsey, R. and L. Razzolini (2003). Explaining overbidding in first price auctions using controlled lotteries. Experimental Economics 6, 123-140.

Dyer, D., J. Kagel, and D. Levin (1989). Resolving the uncertainty about the number of bidders in independent-private value auctions: An experimental analysis. RAND Journal of Economics 20, 268-279.

Engelbrecht-Wiggans, R. and E. Katok (2005). Experimental and Behavior Economics, Advances in Applied Microeconomics, Volume 13, Chapter 7, pp. 171-196. Elsevier.

Eriksson, T., S. Teyssier, and M. Villeval (2006). Self-selection and the efficiency of tournaments. Working Paper. 
Filiz-Ozbay, E. and E. Ozbay (2007). Auctions with anticipated regret: Theory and experiment. American Economic Review 97, 1407-1418.

Fischbacher, U. (1998). Zurich toolbox for readymade economic experiments. Working Paper.

Garratt, R., M. Walker, and J. Wooders (2008). Behavior in second price auctions by highly experienced eBay buyers and sellers. Working Paper.

Goree, J., C. Holt, and T. Palfrey (2005). Regular quantal response equilibrium. Experimental Economics 8, 347-367.

Issac, R. and D. James (2000). Just who are you calling risk averse? Journal of Risk and Uncertainty 20, 177-187.

Issac, R., S. Pevnitskaya, and K. Schnier (2007). Bidder behavior in sealed bid auctions where the number of bidders is unknown. Working Paper.

Ivanova-Stenzel, R. and T. Salmon (2004). Bidder preferences among auction institutions. Economic Inquiry 42, 223-236.

Ivanova-Stenzel, R. and T. Salmon (2008). Robustness of preferences among auction institutions. Economic Inquiry 46, 355-368.

Kagel, J. (1995). Auctions, Chapter 7. Handbook of Experimental Economics. Princeton University Press.

Kagel, J. and D. Levin (1993). Independent private value auctions: Bidder behaviour in first-, second- and third-price auctions with varying number of bidders. The Economic Journal 103, 868-879.

Kagel, J. and D. Levin (2008). Auctions: A survey of experimental research, 1995-2008. Working Paper.

Lazear, E., U. Malmendier, and R. Weber (2006). Sorting in experiments with applications to social preferences. Working Paper.

Lee, H. and U. Malmendier (2008). The bidder's curse. Working Paper.

Levin, D. and J. Smith (1994). Equilibrium in auctions with entry. American Economic Review 84, $585-599$.

Lucking-Reiley, D. (2005). Experimental Business Research, Volume 2: Economic and Managerial Perspectives, Volume 2, Chapter Experimental Evidence on the Endogenous Entry of Bidders in Internet Auctions, pp. 103-121. Kluwer Academic Publishers.

Niederle, M. and L. Vesterlund (2007). Do women shy away from competition too much? Do men compete too much? Quarterly Journal of Economics 122, 1067-1101. 
Palfrey, T. and S. Pevnitskaya (2008). Endogenous entry and self selection in private value auctions: An experimental study. Journal of Economic Behavior and Organizations 66, 731-747.

Pevnitskaya, S. (2004). Endogenous entry in first-price private value auctions: The self-selection effect. Working Paper. 
Table 1: Over-Entry into Auctions: Competing Against Similar Bidders

\begin{tabular}{lcc}
\hline Case & Mean & Std. Dev. \\
\hline OVERALL & 0.161 & 0.368 \\
SECOND PRICE & 0.316 & 0.467 \\
FIRST PRICE, $N=3$ & 0.109 & 0.313 \\
FIRST PRICE, $N=5$ & 0.058 & 0.235 \\
\hline \hline
\end{tabular}

This table displays the percentage of times bidders were ex ante rational in their WTE measure under the assumption that they thought they were competing against bidders like themselves.

Table 2: Bidding in Second Price Auctions

\begin{tabular}{lccccc}
\hline Variable & Mean & Median & Std. Dev. & p25 & p75 \\
\hline BID & 68.65 & 70.00 & 24.35 & 50.00 & 90.00 \\
VALUATION & 64.54 & 65.00 & 21.40 & 46.00 & 84.00 \\
OVERBID & 0.53 & 1.00 & 0.50 & 0.00 & 1.00 \\
PERCENTAGE OVERBID & 0.28 & 0.15 & 0.32 & 0.06 & 0.38 \\
\hline \hline
\end{tabular}

This data come from second price auctions with 13 females and 15 males. 
Table 3: Overbidding in Second Price Auctions

\begin{tabular}{|c|c|c|c|c|c|}
\hline & (1) & $(2)$ & $(3)$ & $(4)$ & $(5)$ \\
\hline VALUATION & $\begin{array}{c}0.0002 \\
(0.003)\end{array}$ & $\begin{array}{c}0.0006 \\
(0.007)\end{array}$ & $\begin{array}{l}0.003 \\
(0.004)\end{array}$ & $\begin{array}{l}-.002 \\
(0.005)\end{array}$ & $\begin{array}{c}0.0005 \\
(0.004)\end{array}$ \\
\hline MALE & $\begin{array}{c}0.801^{* *} \\
(0.395)\end{array}$ & $\begin{array}{c}0.954^{* *} \\
(0.422)\end{array}$ & $\begin{array}{l}0.609 \\
(0.432)\end{array}$ & $\begin{array}{c}1.030^{* *} \\
(0.429)\end{array}$ & $\begin{array}{c}0.802^{*} \\
(0.437)\end{array}$ \\
\hline EXPERIENCE & $\begin{array}{l}-.467 \\
(0.599)\end{array}$ & $\begin{array}{l}-.880 \\
(0.602)\end{array}$ & $\begin{array}{c}-.010 \\
(0.71)\end{array}$ & $\begin{array}{l}-.188 \\
(0.564)\end{array}$ & $\begin{array}{l}-.870 \\
(0.623)\end{array}$ \\
\hline RISK & $\begin{array}{c}-.354^{*} \\
(0.197)\end{array}$ & $\begin{array}{c}-.441^{* * *} \\
(0.164)\end{array}$ & $\begin{array}{c}-.296 \\
(0.22)\end{array}$ & $\begin{array}{c}-.631^{* * *} \\
(0.221)\end{array}$ & $\begin{array}{l}-.257 \\
(0.216)\end{array}$ \\
\hline COMPETITIVE & $\begin{array}{l}-.048 \\
(0.229)\end{array}$ & $\begin{array}{l}0.124 \\
(0.209)\end{array}$ & $\begin{array}{l}-.072 \\
(0.262)\end{array}$ & $\begin{array}{l}-.091 \\
(0.245)\end{array}$ & $\begin{array}{l}-.141 \\
(0.229)\end{array}$ \\
\hline CLARITY & $\begin{array}{l}-.113 \\
(0.194)\end{array}$ & $\begin{array}{c}0.01 \\
(0.215)\end{array}$ & $\begin{array}{l}-.094 \\
(0.202)\end{array}$ & $\begin{array}{l}-.281 \\
(0.197)\end{array}$ & $\begin{array}{l}-.093 \\
(0.191)\end{array}$ \\
\hline HOWOFTEN & $\begin{array}{l}0.173 \\
(0.277)\end{array}$ & $\begin{array}{l}0.359 \\
(0.284)\end{array}$ & $\begin{array}{l}0.026 \\
(0.322)\end{array}$ & $\begin{array}{l}0.322 \\
(0.294)\end{array}$ & $\begin{array}{l}0.024 \\
(0.283)\end{array}$ \\
\hline PERIOD & $\begin{array}{l}-.019 \\
(0.022)\end{array}$ & $\begin{array}{l}-.014 \\
(0.061)\end{array}$ & $\begin{array}{l}0.038 \\
(0.096)\end{array}$ & $\begin{array}{l}0.027 \\
(0.061)\end{array}$ & $\begin{array}{c}-.088^{*} \\
(0.046)\end{array}$ \\
\hline CONSTANT & $\begin{array}{l}2.105 \\
(1.962)\end{array}$ & $\begin{array}{l}0.356 \\
(4.024)\end{array}$ & $\begin{array}{r}-1.347 \\
(5.538)\end{array}$ & $\begin{array}{l}2.189 \\
(1.525)\end{array}$ & $\begin{array}{c}5.401^{*} \\
(3.083)\end{array}$ \\
\hline CASE DUMMIES & YES & $\mathrm{N} / \mathrm{A}$ & $\mathrm{N} / \mathrm{A}$ & $\mathrm{N} / \mathrm{A}$ & $\mathrm{N} / \mathrm{A}$ \\
\hline PERIOD DUMMIES & YES & YES & YES & YES & YES \\
\hline CONSTANT & $\begin{array}{l}0.806 \\
(1.285)\end{array}$ & $\begin{array}{l}1.348 \\
(1.389)\end{array}$ & $\begin{array}{l}0.383 \\
(1.734)\end{array}$ & $\begin{array}{l}0.051 \\
(1.475)\end{array}$ & $\begin{array}{l}1.224 \\
(1.424)\end{array}$ \\
\hline $\mathrm{N}$ & 805 & 226 & 177 & 188 & 209 \\
\hline Pseudo $\mathrm{R}^{2}$ & 0.0892 & 0.0753 & 0.1741 & 0.1363 & 0.1248 \\
\hline CASES & ALL & 1 & 2 & 3 & 4 \\
\hline
\end{tabular}

The table displays results from a probit model of whether the subject bid more than his value in the second price auction.

In all specifications standard errors are clustered by subjects.

All specifications include 5-period-length dummies and subject survey responses.

${ }^{*},{ }^{* *},{ }^{* *}$ imply significance at the $10 \%, 5 \%$ and $1 \%$ level, respectively. 
Table 4: Bidding in Second Price Auctions

\begin{tabular}{|c|c|c|c|c|}
\hline & (1) & $(2)$ & $(3)$ & (4) \\
\hline VALUE & $\begin{array}{c}-.004^{* * *} \\
(0.001)\end{array}$ & $\begin{array}{c}-.004^{* * *} \\
(0.001)\end{array}$ & $\begin{array}{c}-.004^{* * *} \\
(0.001)\end{array}$ & $\begin{array}{c}-.004^{* * *} \\
(0.001)\end{array}$ \\
\hline MALE & $\begin{array}{c}0.119^{*} \\
(0.066)\end{array}$ & $\begin{array}{c}0.119^{*} \\
(0.066)\end{array}$ & $\begin{array}{c}0.118^{*} \\
(0.066)\end{array}$ & $\begin{array}{c}0.118^{*} \\
(0.067)\end{array}$ \\
\hline EXPERIENCE & $\begin{array}{c}-.193^{*} \\
(0.101)\end{array}$ & $\begin{array}{c}-.194^{*} \\
(0.101)\end{array}$ & $\begin{array}{c}-.192^{*} \\
(0.101)\end{array}$ & $\begin{array}{c}-.192^{*} \\
(0.101)\end{array}$ \\
\hline RISK & $\begin{array}{l}-.004 \\
(0.033)\end{array}$ & $\begin{array}{l}-.003 \\
(0.033)\end{array}$ & $\begin{array}{l}-.004 \\
(0.033)\end{array}$ & $\begin{array}{l}-.003 \\
(0.033)\end{array}$ \\
\hline COMPETITIVE & $\begin{array}{l}-.028 \\
(0.037)\end{array}$ & $\begin{array}{l}-.029 \\
(0.036)\end{array}$ & $\begin{array}{l}-.028 \\
(0.036)\end{array}$ & $\begin{array}{l}-.029 \\
(0.036)\end{array}$ \\
\hline CLARITY & $\begin{array}{c}0.01 \\
(0.033)\end{array}$ & $\begin{array}{c}0.01 \\
(0.033)\end{array}$ & $\begin{array}{c}0.01 \\
(0.033)\end{array}$ & $\begin{array}{c}0.01 \\
(0.033)\end{array}$ \\
\hline HOWOFTEN & $\begin{array}{l}0.031 \\
(0.042)\end{array}$ & $\begin{array}{l}0.031 \\
(0.041)\end{array}$ & $\begin{array}{l}0.031 \\
(0.042)\end{array}$ & $\begin{array}{l}0.031 \\
(0.042)\end{array}$ \\
\hline PERIOD & $\begin{array}{c}-.001 \\
(0.0007)\end{array}$ & $\begin{array}{l}-.001 \\
(0.001)\end{array}$ & $\begin{array}{c}-.001 \\
(0.0007)\end{array}$ & $\begin{array}{l}-.001 \\
(0.001)\end{array}$ \\
\hline CASE DUMMIES & NO & $\mathrm{NO}$ & YES & YES \\
\hline PERIOD DUMMIES & $\mathrm{NO}$ & YES & $\mathrm{NO}$ & YES \\
\hline CONSTANT & $\begin{array}{c}1.379^{* * *} \\
(0.249)\end{array}$ & $\begin{array}{c}1.398^{* * *} \\
(0.275)\end{array}$ & $\begin{array}{c}1.368^{* * *} \\
(0.249)\end{array}$ & $\begin{array}{c}1.387^{* * *} \\
(0.276)\end{array}$ \\
\hline $\mathrm{N}$ & 805 & 805 & 805 & 805 \\
\hline $\mathrm{R}^{2}$ & 0.11 & 0.114 & 0.111 & 0.115 \\
\hline
\end{tabular}

The dependent variable is the fraction of value bid by subjects in second price auctions. In all specifications standard errors are clustered by subjects.

All specifications include subject survey responses.

PERIOD DUMMIES are dummies of period length 5 .

Each regression was also done by case and no interesting additional results were found. ${ }^{*},{ }^{* *},{ }^{* * *}$ imply significance at the $10 \%, 5 \%$ and $1 \%$ level, respectively. 
Table 5: The Selection Effect on Bidding in First Price Auctions

\begin{tabular}{|c|c|c|c|c|}
\hline & $(1)$ & $(2)$ & $(3)$ & $(4)$ \\
\hline ENTRYCOST & $\begin{array}{c}0.009^{* * *} \\
(0.003)\end{array}$ & & $\begin{array}{c}0.006^{* * *} \\
(0.002)\end{array}$ & \\
\hline MAXENTRYFEE & & $\begin{array}{l}0.006 \\
(0.005)\end{array}$ & & $\begin{array}{l}0.003 \\
(0.004)\end{array}$ \\
\hline MALE & $\begin{array}{c}0.199^{* * *} \\
(0.06)\end{array}$ & $\begin{array}{c}0.243^{* *} \\
(0.117)\end{array}$ & $\begin{array}{c}0.089^{* *} \\
(0.04)\end{array}$ & $\begin{array}{l}0.073 \\
(0.082)\end{array}$ \\
\hline FOURBIDDERS & $\begin{array}{c}0.15^{* * *} \\
(0.05)\end{array}$ & $\begin{array}{c}0.147^{* * *} \\
(0.048)\end{array}$ & $\begin{array}{c}0.077^{* * *} \\
(0.029)\end{array}$ & $\begin{array}{c}0.067^{* *} \\
(0.028)\end{array}$ \\
\hline CASE 1 & & & $\begin{array}{c}0.036^{* *} \\
(0.018)\end{array}$ & $\begin{array}{c}0.037^{* *} \\
(0.017)\end{array}$ \\
\hline MALE $\times$ FOURBIDDERS & $\begin{array}{c}-.193^{* * *} \\
(0.063)\end{array}$ & $\begin{array}{c}-.192^{* * *} \\
(0.065)\end{array}$ & $\begin{array}{l}-.038 \\
(0.038)\end{array}$ & $\begin{array}{l}-.028 \\
(0.037)\end{array}$ \\
\hline MALE $\times$ ENTRYCOST & $\begin{array}{l}-.009 \\
(0.007)\end{array}$ & & $\begin{array}{c}-.005^{*} \\
(0.003)\end{array}$ & \\
\hline MALE $\times$ MAXENTRYFEE & & $\begin{array}{l}-.005 \\
(0.007)\end{array}$ & & $\begin{array}{l}-.001 \\
(0.004)\end{array}$ \\
\hline FOURBIDDERS $\times$ CASE 1 & & & $\begin{array}{c}-.085^{* * *} \\
(0.028)\end{array}$ & $\begin{array}{c}-.084^{* * *} \\
(0.027)\end{array}$ \\
\hline EXPERIENCE & $\begin{array}{l}-.071 \\
(0.062)\end{array}$ & $\begin{array}{l}-.064 \\
(0.063)\end{array}$ & $\begin{array}{l}0.012 \\
(0.051)\end{array}$ & $\begin{array}{l}0.011 \\
(0.052)\end{array}$ \\
\hline RISK & $\begin{array}{l}0.026 \\
(0.017)\end{array}$ & $\begin{array}{l}0.023 \\
(0.017)\end{array}$ & $\begin{array}{l}-.002 \\
(0.013)\end{array}$ & $\begin{array}{l}-.001 \\
(0.014)\end{array}$ \\
\hline COMPETITIVE & $\begin{array}{c}0.018^{*} \\
(0.01)\end{array}$ & $\begin{array}{l}0.016 \\
(0.014)\end{array}$ & $\begin{array}{l}0.012 \\
(0.012)\end{array}$ & $\begin{array}{l}0.012 \\
(0.012)\end{array}$ \\
\hline CLARITY & $\begin{array}{l}0.011 \\
(0.014)\end{array}$ & $\begin{array}{l}0.011 \\
(0.013)\end{array}$ & $\begin{array}{l}-.006 \\
(0.014)\end{array}$ & $\begin{array}{l}-.005 \\
(0.015)\end{array}$ \\
\hline HOWOFTEN & $\begin{array}{l}0.006 \\
(0.038)\end{array}$ & $\begin{array}{c}0.002 \\
(0.04)\end{array}$ & $\begin{array}{l}-.044 \\
(0.037)\end{array}$ & $\begin{array}{l}-.046 \\
(0.037)\end{array}$ \\
\hline PERIOD & $\begin{array}{l}-.004 \\
(0.013)\end{array}$ & $\begin{array}{l}-.003 \\
(0.014)\end{array}$ & $\begin{array}{l}-.002 \\
(0.006)\end{array}$ & $\begin{array}{l}-.001 \\
(0.006)\end{array}$ \\
\hline SEEVALUATION & & & $\begin{array}{l}-.002 \\
(0.015)\end{array}$ & $\begin{array}{c}0.00009 \\
(0.016)\end{array}$ \\
\hline PERIOD DUMMIES & YES & YES & YES & YES \\
\hline CONSTANT & $\begin{array}{c}0.454^{* * *} \\
(0.089)\end{array}$ & $\begin{array}{c}0.421^{* * *} \\
(0.128)\end{array}$ & $\begin{array}{c}0.924^{* *} \\
(0.415)\end{array}$ & $\begin{array}{l}0.86^{*} \\
(0.456)\end{array}$ \\
\hline Cases & 1 & 1 & 1 and 2 & 1 and 2 \\
\hline Obs. & 153 & 153 & 622 & 622 \\
\hline $\mathrm{R}^{2}$ & 0.174 & 0.155 & 0.082 & 0.07 \\
\hline
\end{tabular}

The dependent variable is the fraction of value bid by subjects.

The first two columns use only case 1 when bidders can't see their valuations; the rest use cases 1 and 2 . In all specifications the standard errors are clustered by subject.

PERIOD DUMMIES are dummies of period length 5 .

${ }^{*},{ }^{* *},{ }^{* * *}$ imply significance at the $10 \%, 5 \%$ and $1 \%$ level, respectively. 
Table 6: Potential for Spite Motive

\begin{tabular}{lccccc}
\hline & \multicolumn{2}{c}{ Case 1 } & \multicolumn{2}{c}{ Case 2 } & \\
& Mean & Std. Dev. & Mean & Std. Dev. & t-stat \\
\hline All $v$ & 0.799 & 0.295 & 0.844 & 0.327 & -1.103 \\
$v<62$ & 0.803 & 0.405 & 0.852 & 0.494 & -0.468 \\
\hline \hline
\end{tabular}

This table displays the percentage value bid when bidders end up facing four bidders and knew their value at the entry stage.

Table 7: JOY Estimates from Bidding in Second Price Auctions

\begin{tabular}{lccc}
\hline & Pooled & Men & Women \\
\hline$\widehat{\theta_{A}}$ & 4.229 & 4.813 & 3.472 \\
$\widehat{\theta_{M}}$ & 1.093 & 1.105 & 1.078 \\
\hline
\end{tabular}

The table displays the implied "joy of winning" parameters from second price auctions.

Table 8: RA Estimates from Bidding in First Price Auctions with and without JOY

\begin{tabular}{lccc}
\hline & RA Only & RA and Additive Joy & RA and Multiplicative Joy \\
& $\widehat{\alpha}$ & $\widehat{\alpha\left(\theta_{A}\right)}$ & $\widehat{\alpha\left(\theta_{M}\right)}$ \\
\hline Pooled & 0.602 & 0.735 & 0.755 \\
Men & 0.621 & 0.825 & 0.843 \\
Women & 0.591 & 0.666 & 0.667 \\
\hline
\end{tabular}

The table displays the estimated implied risk parameters from first price auctions for different assumptions about the presence and form of JOY, assuming CRRA preferences. 


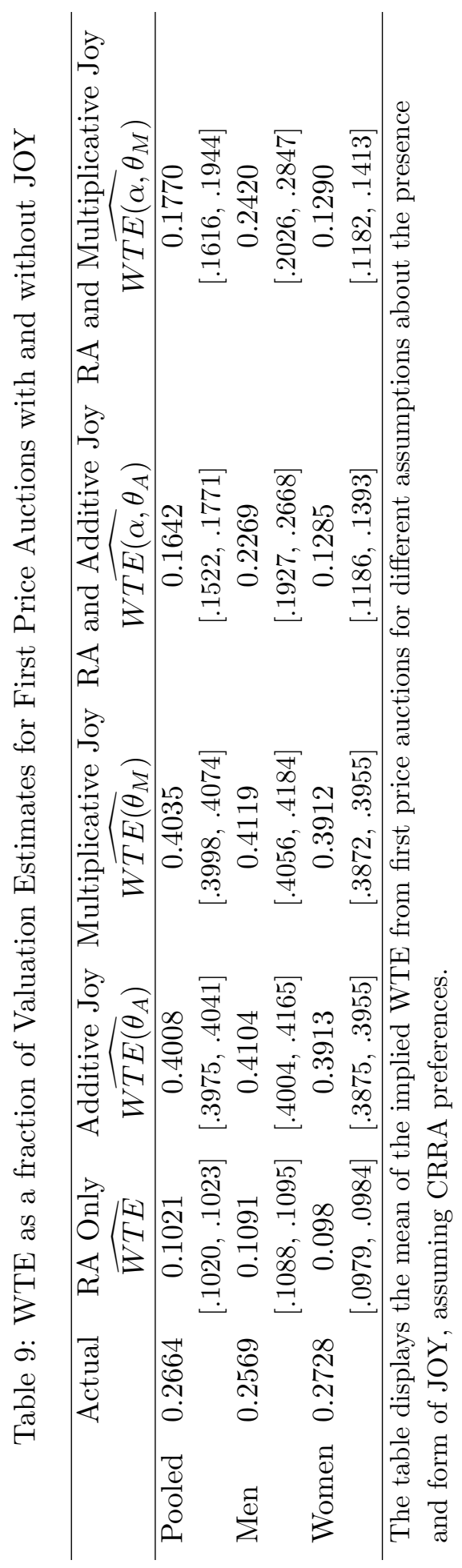


Overentry vs. Valuation: RA and No JOY
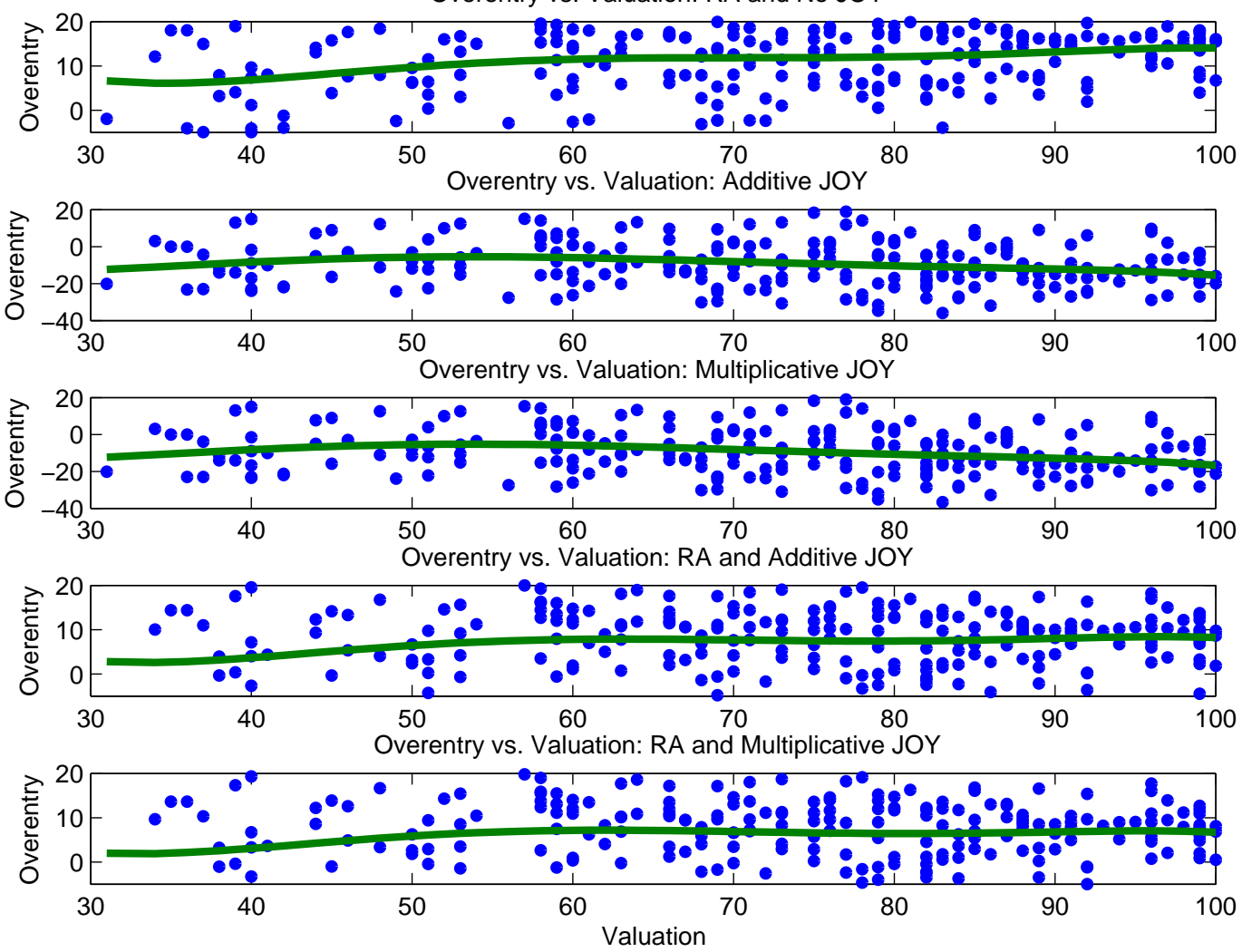

Figure 1: Plot of (WTE- $\widehat{W T E}$ ) as a function of value for various models. 